\title{
Robust Estimation for a CSTR Using a High Order Sliding Mode Observer and an Observer-Based Estimator
}

\section{Estimación Robusta para un CSTR Usando Observadores por Modos Deslizantes de Alto orden y un Estimador Basado en Observador}

\section{Estimação Robusta para um CSTR Usando uma Ordem Elevada Modo Deslizante Observador e um Estimador Baseado em Observador}

\author{
Héctor A. Botero ${ }^{1 *}$; Esteban Jiménez-Rodríguez; Oscar Jaramillo; Juan Diego Sánchez Torres² \\ ${ }^{1}$ Universidad Nacional de Colombia, Sede Medellín, Grupo de Investigación en Procesos Dinámicos-Kalman \\ Crr 80 \# 65-223. Medellín, Colombia \\ 2Departamento de Matemáticas y Física, ITESO - Universidad Jesuita de Guadalajara, México. \\ *habotero@unal.edu.co
}

Fecha Recepción: 12 de junio de 2015 Fecha Aceptación: 12 de septiembre de 2016

\begin{abstract}
This paper presents an estimation structure for a continuous stirred-tank reactor, which is comprised of a sliding mode observer-based estimator coupled with a high-order sliding-mode observer. The whole scheme allows the robust estimation of the state and some parameters, specifically the concentration of the reactive mass, the heat of reaction and the global coefficient of heat transfer, by measuring the temperature inside the reactor and the temperature inside the jacket. In order to verify the results, the convergence proof of the proposed structure is done, and numerical simulations are presented with noiseless and noisy measurements, suggesting the applicability of the posed approach.
\end{abstract}

Keywords: observers for chemical processes, robust observer design, sliding mode algorithms, uncertain systems.

\section{Resumen}

Este trabajo presenta una estructura de estimación para un reactor de tanque agitado en continuo, la cual se compone de un estimador basado en observador por modos deslizantes acoplado con un observador por modos deslizantes de alto orden. Todo el esquema permite la estimación robusta del estado y algunos parámetros, concretamente la concentración de la masa reactiva, el calor de reacción y el coeficiente global de transferencia de calor, a partir de la medición de las temperaturas al interior del reactor y de la chaqueta. Para verificar los resultados, se realizan pruebas de convergencia de la estructura propuesta, y se presentan simulaciones numéricas con mediciones ruidosas y sin ruido, lo que sugiere la aplicabilidad del enfoque planteado.

Palabras clave: observadores para procesos químicos, diseño de observadores robustos, algoritmos de modos deslizantes, sistemas con incertidumbre. 


\section{Resumo}

Este trabalho apresenta uma estrutura de estimativa para um reator de tanque agitado continuamente, que é composta por um estimador baseado em observador deslizante de modo acoplado com um alto ordem modo deslizante observador. Todo o esquema permite a estimativa robusta do estado e alguns parâmetros, a saber, a concentração da massa de reação, o calor da reação e o coeficiente de transferência total de calor, a partir da medição da temperatura no interior do reator e da jaqueta. Para verificar os resultados, as evidências de convergência da estrutura proposta são feitas, e simulações numéricas são apresentadas com medidas ruidosas e sem ruído, o que sugere a aplicação da abordagem proposta.

Palabras-chave: observadores do processo químico, projeto observadores robustos, modos deslizantes algoritmos, sistemas com a incerteza.

\section{Introduction}

For numerous applications, including chemical processes, it is well known that nonlinear state observers, parameter and unknown inputs estimators have been becoming of great interest. The main uses for those methods are the design of observer-based controllers, the synthesis of fault detection and isolation methods [1], among other applications. An important class of nonlinear observers is the Sliding Mode Observers (SMO) [24], which have the main features of the Sliding Mode (SM) algorithms. Those algorithms, are proposed with the idea to drive the dynamics of a system to a sliding manifold, that is an integral manifold with finite reaching time [5], exhibiting very interesting features such as work with reduced observation error dynamics, the possibility of obtain a step by step design, robustness and insensitivity under parameter variations and external disturbances, and finite-time stability $[2,6]$. In addition, the last feature can be extended to uniform finite time stability [7] also known as fixed-time stability [8], allowing the controllers and estimators to converge with a settling-time independent to the initial conditions. On the other hand, it is said usually that the sliding mode algorithms present two main disadvantages:

i. they are usually assumed to be more sensitive to noise than linear controllers and estimators [9], and

ii. the so-called chattering which is a high frequency oscillation due to the effect of discontinuities of the functions used to induce sliding modes (e.g. the sign function) on the unmodeled dynamics of the system [2].

However, for the disadvantage (i), using the steady state error as performance index, it is shown that, under the bounded disturbance hypothesis, linear and discontinuous algorithms are equally sensitive to noise. Therefore, discontinuous algorithms are a better choice under both noise and disturbance presence conditions [10]. Besides, for the disadvantage (ii), several approaches have been proposed to reduce or avoid chattering. A first example is the use of continuous and smooth approximations of the sign function as linear saturation or sigmoid functions [11], with this solution only a quasi-sliding motion can be forced in a vicinity of the desired manifold, decreasing the performance and the robustness of the algorithm [12]. Another approach to induce sliding modes reducing chattering is to use continuous but nondifferentiable functions or with discontinuous derivatives, instead of a discontinuous function. These methods are the so-called High Order Sliding Mode (HOSM) algorithms [13], extending the idea of the SM actuating on the time derivatives of the sliding manifold, preserving the main features of the original SM approach. In addition, for a SMO design case, the chattering reduces to a numerical problem [14]. Hence, some SMO have attractive properties similar to those of the Kalman filter but with simpler implementation [15]. For chemical processes, SM observers have been applied for several cases. Some examples are shown in [16-19]. The idea of coupling an observer with an Observer-Based Estimator (OBE) was used in [20] and, the idea of applying a High Order Sliding Mode Observer (HOSMO) for state and parameter estimation in a Continuous StirredTank Reactor (CSTR), assuming the parameter to be estimated as an unknown input, was introduced by [21]. Here, measuring the temperature inside the reactor, the observer estimates the heat of reaction, and the concentration of the reactive. In addition, in order to facilitate the estimation procedure, the global heat transfer coefficient was assumed to be a known constant. No dynamics of the temperature inside the jacket were considered 
in the mentioned approach. This paper proposes an extension of the last approaches, considering the global heat transfer coefficient as an unknown parameter to be estimated. This assumption conduces to a better approximation of the CSTR real operation conditions. As a first step, an OBE for the global heat transfer coefficient estimation is used. With this estimation, a HOSMO for state and input estimation [22] is used to estimate the heat of reaction, and the concentration of reactive. The heat of reaction is a parameter which is considered to be an unknown input for the observer design. The HOSMO is based on a real-time differentiator [23]. In the following, the next section presents the mathematical model of the CSTR. Then, the estimation structure will be described. The paper continues with the results of numerical simulation. Finally, the conclusions of this paper are presented.

\section{Mathematical Model for the CSTR}

The CSTR considered performs an exothermic chemical reaction from the reactant $\Gamma$ to the product $\Phi(\Gamma \rightarrow \Phi)$. This plant has also a recirculation flow in the jacket, which allows improving its controller design [24].

The state equations of the CSTR are presented in two subsystems as follows, with the outputs $T$ and $T j$ :

$$
\left\{\dot{\mathrm{T}}_{j}=\frac{F_{j f}}{V_{j}}\left(T_{j f}-T_{j}\right)-\frac{\Lambda}{\rho_{j} C_{p j} V_{j}}\left(T_{j}-T\right)\right.
$$

Here, $F$ is the flow into the reactor, $V$ is the volume of the reaction mass, $C_{i n}$ is the reactive input concentration, $C_{A}$ is the concentration of the reactive inside the reactor, $k_{0}$ is the Arrhenius kinetic constant, $E$ is the activation energy, $R$ is the universal gas constant, $T$ is the temperature inside the reactor, $T_{\text {in }}$ is the inlet temperature of the reactant, $\Delta H$ is the heat of reaction (being an exothermic reaction, this corresponds to the released energy during the reaction), and in this article is considered an unknown input because it is an uncertain parameter, $\rho$ is the density of the mixture in the reactor, $C_{p}$ is the heat capacity of food, the parameter $\Lambda=U A$ is the global coefficient of heat transfer, where $U$ is the overall coefficient of heat transfer and $A$ is the heat transfer area, $T_{j}$ is the temperature inside the jacket, $F_{j f}$ is the feeding flow, $V_{j}$ is the jacket volume, $T_{j f}$ is the inlet temperature to the jacket, $\rho_{j}$ is the density of jacket flow, and $C_{p j}$ is the heat capacity of the jacket flow [24].

\section{Estimation System Design}

In this section the estimation system for the CSTR is proposed, it estimates the following variables:

- The concentration of the reactant inside the reactor, $C_{A}$ (state variable), due to expensive sensors.
- The global coefficient of heat transfer, $\Lambda$ (parameter), which depends on tank level (although in this paper it was considered constant), the stirring speed inside the reactor, the cleaning degree of the surface inside the reactor, and speed of the cooling flow inside the jacket; making its estimation a hard task [25].

- The heat of reaction, $\Delta H$ (parameter), which is uncertain due to experimental measurement complexity of thermal and kinetic phenomena that involve it [18].

Considering Subsystem (1), it can be noted that the global coefficient of heat transfer, $\Lambda$, is the only unknown parameter.

Taking advantage of this characteristic, an estimation system based on cascade connection of an OBE with a HOSMO is proposed as follows:

- Using measurements of $T, T_{j}$ and, an OBE based on Subsystem (1), an estimation of the parameter $\Lambda,(\widehat{\Lambda})$, is obtained.

- Using measurements of $T, T$, the estimated parameter $\hat{\Lambda}$ and, a HOSMO based on Subsystem (2), estimations of the state variable $C_{A}\left(\widehat{C_{A}}\right)$, and the parameter $\Delta H(\widehat{\Delta H})$ are obtained.

For the last case, the HOSMO structure allows to consider the parameter $\Delta H$ as an unknown input. 
With this assumption, the estimation system is robust against variations of $\Delta H$.

The whole structure for state and parameter estimation of CSTR is shown in Figure 1.

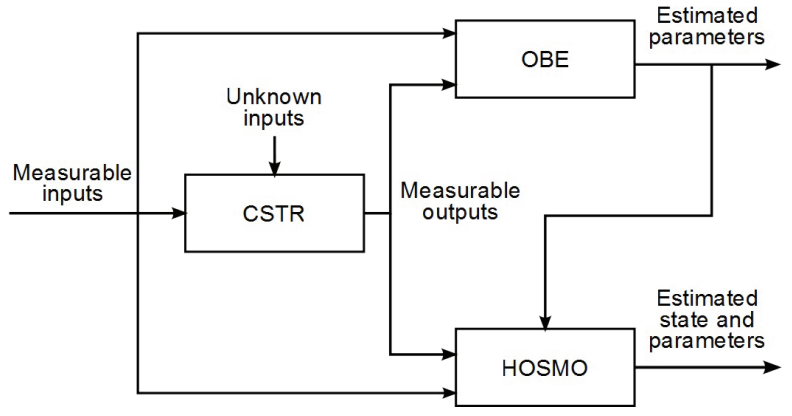

Figure 1. Structure for state and parameter estimation of CSTR.

Regarding the cascade structure of the estimation system, it will be started with the parameter $\Lambda$ estimation.

At first, it must be noted that the HOSMO allows the joint estimation of state and parameters, considering the last ones as unknown inputs. However, it is no possible to fulfill the requirement by the HOSM in order to estimate simultaneously the parameters $\Lambda$ and $\Delta H$.

Therefore, the use of an OBE to estimate $\Lambda$ is proposed here. Initially, it is highlighted that the proposed scheme, in addition to the temperature measurement $T$, also requires an estimation of its time derivative $\dot{T}$.
This estimation is performed by using a robust exact sliding mode differentiator [23], with the following structure:

$$
\begin{aligned}
& \dot{z_{0}}=-\lambda_{0} L^{\frac{1}{3}}\left[z_{0}-T\right]^{\frac{2}{3}}+z_{1} \\
& \dot{z_{1}}=-\lambda_{1} L^{\frac{1}{2}}\left[z_{1}-\dot{z}_{0}\right]^{\frac{1}{2}}+z_{2} \\
& \dot{z_{2}}=-\lambda_{2} L\left[z_{2}-\dot{z_{1}}\right]^{0}
\end{aligned}
$$

where it is defined the function $\left[\left.\bullet\right|^{\alpha}=|\bullet|^{\alpha}\right.$ sign $(\bullet)$ for $\alpha \geq 0 ; z_{0}$ is the estimation of $T, z_{1}$ is the estimation of its time derivative $\dot{\mathrm{T}}$ and, $z_{2}$ is the estimation of $\ddot{\mathrm{T}}$, with $\lambda_{0}, \lambda_{1}, \lambda_{2}$ being positive gains. Let the third derivative $T^{(3)}$ be bounded as $\left|T^{(3)}\right|<\delta T$ for all the time with $\delta T$ a positive constant, therefore, the gain $\mathrm{L}$ must be such that $\mathrm{L}>\delta T$.

Note that a second order differentiator is used instead of a first order one, the variable $z_{2}$ is not used, the main reason for this selection is to reduce the presence of numerical chattering on the estimated variables.

\section{OBE design}

Taking into account the Subsystem (1) and using the jacket temperature equation $T_{j}$ as coupling equation to calculate $\Lambda$, an OBE based on the generalized super-twisting algorithm [7] is proposed as follows:

$$
\begin{aligned}
& \left\{\dot{\hat{T}}=\frac{F_{j f}}{V_{j}}\left(T_{j f}-\hat{T}_{j}\right)-\frac{\hat{\Lambda}}{\rho_{j} C_{p j} V_{j}}\left(T_{j}-z_{0}\right)+k_{1} \phi_{1}\left(\widetilde{T}_{j}\right)\right. \\
& \dot{\hat{\Lambda}}=k_{2} \frac{\rho_{j} C_{p j} V_{j}}{\delta_{j}} \phi_{2}\left(\widetilde{T}_{j}\right)
\end{aligned}
$$

where $\widetilde{T}_{j}=T_{j}-\widehat{T}_{j}$. The OBEinputinjectionsaregiven by $\phi_{1}\left(\widetilde{T}_{\mathrm{j}}\right)=\left|\widetilde{\mathrm{T}}_{\mathrm{j}}\right|^{\frac{1}{2}}+\mu\left|\widetilde{\mathrm{T}}_{\mathrm{j}}\right|^{\frac{3}{2}}$ and, $\left.\phi_{2}\left(\widetilde{\mathrm{T}}_{\mathrm{j}}\right)=\frac{1}{2} \mid \widetilde{\mathrm{T}}_{\mathrm{j}}\right]^{0}+2 \mu \widetilde{\mathrm{T}}_{\mathrm{j}}+\frac{3}{2} \mu^{2}\left|\widetilde{\mathrm{T}}_{\mathrm{j}}\right|^{2}$ with $\mu \geq 0$. Finally, $k_{1}$ and $k_{2}$ are the OBE gains. The gain $\delta j$ is a positive constant which takes the value of a lower bound for $\left|z_{0}-T_{j}\right|$, the existence of this parameter is verified taking into account that all the temperatures are measured in Kelvin degrees and the condition $z_{0}>T_{j}$ for all the time.

Note that the system (4) can be considered as a second order sliding mode extension of the linear OBE presented in [26].

\section{HOSMO design}

Once the estimation of $\Lambda$ is obtained, a HOSMO of the form presented in [22] is designed based on Subsystem (2). This observer provides an estimation of the state variable $C_{A}$ and the parameter $\Delta H$.

For this case, the parameter $\Delta H$ is considered as an unknown input. It is observed that the output $T$ has a relative degree equal to one with respect with the unknown input $\Delta H$, therefore $\Delta H$ can be written in terms of $T$ and its time derivative $\dot{T}$ as follows from (2). 


$$
\Delta H=-\left(\frac{k_{0} C_{A}}{\rho C_{P}} e^{-\frac{E}{R T}}\right)^{-1}\left(\dot{T}-\frac{F}{V}\left(T_{i n}-T\right)-\frac{\Lambda}{\rho C_{P} V}\left(T_{j}-T\right)\right)
$$

wThus, calculating the time derivatives of the output (3), the HOSMO structure is $T$ using the robust exact sliding mode differentiator

$$
\begin{gathered}
\dot{C_{A}}=\frac{F}{V}\left(C_{i n}-\hat{C}_{A}\right)-k_{0} \hat{C}_{A} e^{-\frac{E}{R z_{0}}} \\
\dot{\Delta H}=-\frac{1}{\tau}\left[\left(\frac{k_{0} \hat{C}_{A}}{\rho C_{P}} e^{-\frac{E}{R z_{0}}}\right)^{-1}\left(z_{1}-\frac{F}{V}\left(T_{i n}-z_{0}\right)-\frac{\hat{\Lambda}}{\rho C_{P} V}\left(\hat{T}_{j}-z_{0}\right)\right)+\hat{\Delta H}\right]
\end{gathered}
$$

where $\widehat{\Delta H}$ is the estimation of $\Delta H$.

\section{Complete estimation scheme}

From (4)-(3), the complete estimation scheme is given by the following system:

$$
\begin{aligned}
& \left\{\begin{array}{c}
\dot{z_{0}}=-\lambda_{0} L^{\frac{1}{3}}\left[z_{0}-T\right]^{\frac{2}{3}}+z_{1} \\
\dot{z_{1}}=-\lambda_{1} L^{\frac{1}{2}}\left[z_{1}-\dot{z}_{0}\right]^{\frac{1}{2}}+z_{2} \\
\dot{z_{2}}=-\lambda_{2} L\left[z_{2}-\dot{z_{1}}\right]^{0}
\end{array}\right. \\
& \left\{\begin{array}{c}
\dot{\hat{T}}_{j}=\frac{F_{j f}}{V_{j}}\left(T_{j f}-\hat{T}_{j}\right)-\frac{\hat{\Lambda}}{\rho_{j} C_{p j} V_{j}}\left(T_{j}-z_{0}\right)+k_{1} \phi_{1}\left(\widetilde{T}_{j}\right) \\
\dot{\hat{\Lambda}}=k_{2} \frac{\rho_{j} C_{p j} V_{j}}{\delta_{j}} \phi_{2}\left(\widetilde{T}_{j}\right)
\end{array}\right. \\
& \left\{\begin{array}{c}
\dot{\hat{C}}_{A}=\frac{F}{V}\left(C_{i n}-\hat{C}_{A}\right)-k_{0} \hat{C}_{A} e^{-\frac{E}{R z_{0}}} \\
\dot{\hat{H}}=-\frac{1}{\tau}\left[\left(\frac{k_{0} \hat{C}_{A}}{\rho C_{P}} e^{-\frac{E}{R z_{0}}}\right)^{-1}\left(z_{1}-\frac{F}{V}\left(T_{i n}-z_{0}\right)-\frac{\hat{\Lambda}}{\rho C_{P} V}\left(\hat{T}_{j}-z_{0}\right)\right)+\Delta \hat{H}\right]
\end{array}\right.
\end{aligned}
$$

which is a coupled system formed of seven differential equations.

\section{Convergence analysis}

The convergence analysis for the system (6)-(8) is performed by analyzing the stability of the error system.

$$
\left\{\begin{array}{c}
\dot{\widetilde{z}}_{0}=-\lambda_{0} L^{\frac{1}{3}}\left[\widetilde{z}_{0}\right]^{\frac{2}{3}}+\widetilde{z}_{1} \\
\dot{\tilde{z}_{1}}=-\lambda_{1} L^{\frac{1}{2}}\left[z_{1}-\dot{z}_{0}\right]^{\frac{1}{2}}+\widetilde{z}_{2} \\
\dot{\widetilde{z}}_{2}=-\lambda_{2} L\left[z_{2}-\dot{z}_{1}\right]^{0}-T^{(3)}
\end{array}\right.
$$




$$
\begin{gathered}
\left\{\begin{array}{c}
\dot{\widetilde{T}}_{j}=-\frac{F_{j f}}{V_{j}} \hat{T}_{j}+\frac{1}{\rho_{j} C_{p j} V_{j}}\left(-\widetilde{\Lambda} T_{j}+\Lambda T-\hat{\Lambda} z_{0}\right)-k_{1} \phi_{1}\left(\widetilde{T}_{j}\right) \\
\dot{\tilde{\Lambda}}=-k_{2} \frac{\rho_{j} C_{p j} V_{j}}{\delta_{j}} \phi_{2}\left(\widetilde{T}_{j}\right)+\dot{\Lambda}
\end{array}\right. \\
\left\{\begin{array}{c}
\dot{\widetilde{C}}_{A}=-\frac{F}{V} \widetilde{C}_{A}-k_{0} C_{A} e^{-\frac{E}{R T}}+k_{0} \hat{C}_{A} e^{-\frac{E}{R z_{0}}} \\
\Delta \tilde{\tilde{H}}=-\frac{1}{\tau}\left[\left(\frac{-k_{0} \hat{C}_{A}}{\rho C_{P}} e^{-\frac{E}{R z_{0}}}\right)^{-1}\left(z_{1}-\frac{F}{V}\left(T_{i n}-z_{0}\right)-\frac{\hat{\Lambda}}{\rho C_{P} V}\left(\hat{T}_{j}-z_{0}\right)\right)+\Delta \hat{H}\right]
\end{array}\right]
\end{gathered}
$$

where $\widetilde{\mathrm{z}_{0}}=\mathrm{z}_{0}-\mathrm{T}, \widetilde{\mathrm{z}_{1}}=\mathrm{z}_{1}-\dot{\mathrm{T}}, \tilde{\mathrm{z}_{2}}=\mathrm{z}_{2}-\ddot{\mathrm{T}}, \tilde{\Lambda}=\Lambda-\hat{\Lambda}, \widetilde{\mathrm{C}_{\mathrm{A}}}=C_{A}-\hat{\mathrm{C}_{\mathrm{A}}}$ and $\widetilde{T}_{j}=T_{j}-\widehat{T}_{j}$.

At first, for the system (9), with the third derivative $T^{(3)}$ be bounded as $\left|T^{(3)}\right|<\delta_{T}$ for all the time and
$L>\delta_{T}$, the errors $\widetilde{\mathrm{z}_{0}}, \widetilde{\mathrm{z}_{1}}$ and $\tilde{\mathrm{z}_{2}}$ converge to zero in a finite time $t_{j}>0$ [24].

Now, for the system (10), let = $q=\frac{1}{\rho_{j} C_{p j} V_{j}}\left[-\tilde{\Lambda} T_{j}+\Lambda T-\hat{\Lambda} z_{0}\right]$, hence

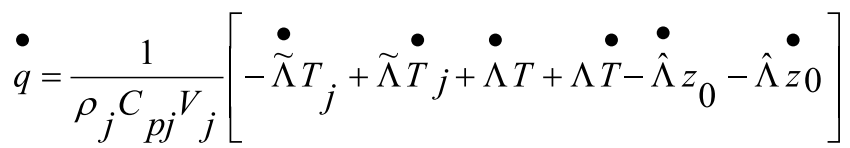

$$
\begin{aligned}
& =\frac{1}{\rho_{j} C_{p j} V_{j}}\left[-(\dot{\Lambda}-\hat{\Lambda}) T_{j}-\widetilde{\Lambda} T_{j}+\dot{\Lambda} T+\Lambda \vec{T}-\hat{\Lambda} z_{0}-\hat{\Lambda} z_{0}\right] \\
& =\frac{1}{\rho_{j} C_{p j} V_{j}}\left[-\left(z_{0}-T_{j}\right) \hat{\Lambda}+\left(T-T_{j}\right) \dot{\Lambda}+\widetilde{\Lambda} \dot{T}_{j}-\Lambda \dot{\Lambda}-\hat{\Lambda} z_{0}\right]
\end{aligned}
$$

Therefore, from (4) and (10), it follows:

$$
\begin{gathered}
\dot{\widetilde{T}}_{j}=-\frac{F_{j f}}{V_{j}} \widetilde{T}_{j}+q-k_{1} \phi_{1}\left(\widetilde{T}_{j}\right) \\
\cdot \dot{q}=k_{2} \theta \phi_{2}\left(\widetilde{T}_{j}\right)+\Delta
\end{gathered}
$$

where $\theta=\frac{z_{0}-T}{\delta_{j}}>1$ and

$\Delta=\frac{1}{\rho_{j} C_{p j} V_{j}}\left[\left(T-T_{j}\right) \dot{\Lambda}+\widetilde{\Lambda} \dot{T}_{j}-\Lambda \dot{T}-\hat{\Lambda} z_{0}\right]$ is an unknown but bounded perturbation, $|\Delta|<\delta_{q}$ for all the time, with $\delta_{q}$ a positive constant.

If the gains $k_{1}, k_{2}$ are in the set the system (12) is fixed-time stable [7], that is a sliding mode appears on the manifold $\left(\widetilde{\mathrm{T}}_{\mathrm{j}}, \mathrm{q}\right)=(0,0)$ in a fixed time $t_{q}>0$.

$$
\begin{aligned}
& K=\left\{\left(k_{1}, k_{2}\right) \in \mathfrak{R}^{2} \mid 0<k_{1} \leq \sqrt{\delta_{q}}, k_{2}>\frac{k_{1}^{2}}{4}+\frac{4 \delta_{q}{ }^{2}}{k_{1}{ }^{2}}\right\} \cup \\
& \left\{\left(k_{1}, k_{2}\right) \in \mathfrak{R}^{2} \mid k_{1}>2 \sqrt{\delta_{q}}, k_{2}>2 \delta_{q}\right\}
\end{aligned}
$$


In this form, with $t_{j q}=\max \left(t_{j}, t_{q}\right)$, a sliding mode The motion on the sliding manifold $\left(\widetilde{z_{0}}, \widetilde{z_{1}}, \widetilde{z_{2}}, T_{j}, q\right)=$ appears on the manifold $\left(\widetilde{z_{0}}, \widetilde{z_{1}}, \widetilde{z_{2}}, T_{j}, q\right)=(0,0,0,0,0) \quad(0,0,0,0,0)$ is given by

in a finite time $t_{j q}>0$.

$$
\begin{gathered}
\dot{\widetilde{C}}_{A}=-\frac{F}{V} \widetilde{C}_{A}-k_{0} \widetilde{C}_{A}-k_{0} \widetilde{C}_{A} e^{-\frac{E}{R T}} \\
\dot{\hat{H}}=-\frac{1}{\tau}\left[\left(\frac{-k_{0} \hat{C}_{A}}{\rho C_{p}} e^{-\frac{E}{R z_{0}}}\right)^{-1}\left(\dot{T}-\frac{F}{V}\left(T_{i n}-T\right)-\frac{\Lambda}{\rho C_{P} V}\left(T_{j}-T\right)\right)+\Delta \hat{H}\right]
\end{gathered}
$$

Taking into account that (14) is just a first order low-pass filter for the estimation of $\Delta H$ given by

$$
\left(\dot{T}-\frac{F}{V}\left(T_{i n}-T\right)-\frac{\Lambda}{\rho C_{P} V}\left(T_{j}-T\right)\right)
$$

the stability analysis is completed considering the equation (13). Thus, let the Lyapunov function

$$
\begin{gathered}
\dot{V}=\widetilde{C}_{A}\left(-\frac{F}{V} \widetilde{C}_{A}-k_{0} \widetilde{C}_{A} e^{-\frac{E}{R T}}\right) \\
=-\frac{F}{V} \widetilde{C}_{A}{ }^{2}-k_{0} \widetilde{C}_{A}{ }^{2} e^{-\frac{E}{R T}} \\
<-\frac{F}{V} \widetilde{C}_{A}{ }^{2}
\end{gathered}
$$

Therefore, the error $\widetilde{\mathrm{C}}_{\mathrm{A}}$ is exponentially stable to the equilibrium point zero.

\section{Numerical Simulation Results}

The numerical simulations results of the proposed estimation structure applied to a CSTR are presented in this section. All simulations presented here were conducted using the Euler integration method, with a fundamental step size of $1 \times 10^{-4}$ [min]. The CSTR parameters are shown on Table 1.

Table 1. Nominal Parameters of the CSTR.

\begin{tabular}{cccc}
\hline Parameter & Values [Unit] & Parameter & Values [Unit] \\
\hline$F$ & $0.1605\left[\mathrm{~m}^{3} \mathrm{~min}^{-1}\right]$ & $C_{p}$ & $3571.3\left[\mathrm{Jkg}^{-1}\right]$ \\
$V$ & $2.4069\left[\mathrm{~m}^{3}\right]$ & $U$ & $2.5552 \times 10^{4}\left[\mathrm{~J}\left(\mathrm{minm}^{2} \mathrm{~K}\right)^{-1}\right]$ \\
$C_{i n}$ & $2114.5\left[\mathrm{gmolm}^{3}\right]$ & $A$ & $8.1755\left[\mathrm{~m}^{2}\right]$ \\
$k_{0}$ & $2.8267 \times 10^{11}\left[\mathrm{~min}^{-1}\right]$ & $F_{j f}$ & $0.3376\left[\mathrm{~m}^{3} \mathrm{~min}^{-1}\right]$ \\
$E$ & $75361.14\left[\mathrm{Jgmol}^{-1}\right]$ & $V_{j}$ & $0.24069\left[\mathrm{~m}^{3}\right]$ \\
$R$ & $8.3174\left[\mathrm{Jgmol}^{-1} \mathrm{~K}^{-1}\right]$ & $T_{j f}$ & $279[\mathrm{~K}]$ \\
$T_{i n}$ & $295.22\left[\mathrm{~K}^{\circ}\right]$ & $\rho_{j}$ & $1000\left[\mathrm{kgm}^{3}\right]$ \\
$\Delta H$ & $-9.0712 \times 10^{4}\left[\mathrm{Jgmol}^{-1}\right]$ & $C_{p j}$ & $3728.87\left[\mathrm{Jkg}^{-1}\right]$ \\
$\rho$ & $1000\left[\mathrm{kgm}^{-3}\right]$ & & \\
\hline
\end{tabular}


In order to verify the observer performance in presence of parametric variations, the changes shown in Table 2 were introduced in the simulation. Is worth to notice that this changes are unknown for the proposed estimation system.

Table 2. CSTR Parametric Variations.

\begin{tabular}{ccc}
\hline Parameter & $\begin{array}{c}\text { Variation } \\
\text { Time }\end{array}$ & Variation Magnitude \\
\hline$\Delta H$ & $45 \mathrm{~min}$ & $\begin{array}{c}10 \% \text { Negative step } \\
50 \% \text {-negative } \\
\text { exponential }\end{array}$ \\
\hline
\end{tabular}

The initial conditions for the CSTR were selected to: $T j(0)=284.084[\mathrm{~K}], \quad T(0)=314.7208[\mathrm{~K}] \quad$ and; $C_{A}(0)=907.1774\left[\mathrm{gmolm}^{3}\right]$ and for the observer to: $\hat{T}_{i}(0)=286.9248[\mathrm{~K}], \quad \hat{\Lambda}(0)=1.8801 \times 10^{5}\left[\mathrm{~J} .(\mathrm{minK})^{-1}\right]$, $\hat{C}_{A}(0)=997.8951\left[\mathrm{gmolm}^{-3}\right], \quad z_{0}(0)=314.7208[\mathrm{~K}]$, $\mathrm{z}_{1}(0)=0\left[\mathrm{Kmin}^{-1}\right], \quad \mathrm{z}_{2}(0)=0\left[\mathrm{Kmin}^{2}\right] \quad$ and $\widehat{\Delta H}(0)=-9 \times 104\left[\mathrm{Jgmol}^{-1}\right]$. For the OBE the selected parameter values were adjusted to: $k_{l}=3.4026$, $k_{2}=5.9821 \times 10^{4}$ and $\mu=1$. For HOSMO, the parameters $\lambda_{0}=2, \lambda_{1}=1.5, \lambda_{2}=1.1$ and $L=10$ were used. Finally, the filter constant was adjusted to: $\tau=\frac{1}{2}$.

This section is divided into two parts. In the first part, there is assumed that the temperature measurements are noiseless; in the second part instead, there is included a normally distributed random signal as measurement noise in the temperature.

\section{Noiseless measurements}

In this subsection, there is assumed no noise in the measurements.

Figures 2 to 4 show the concentration of reactive inside the reactor $C_{A}$, the heat of reaction $\Delta H$ and the global coefficient of heat transfer $\Lambda$, respectively, for noiseless measurements.

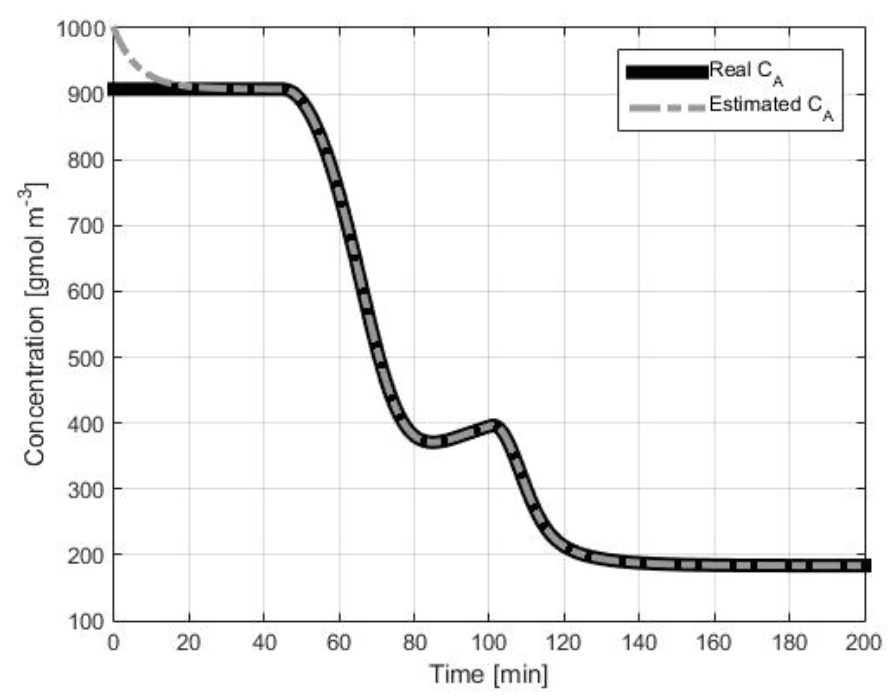

Figure 2. Concentration of the reactive inside the reactor $C A$ (real and estimated).

The estimated concentration converges to the actual concentration, with a settling time of approximately $20 \mathrm{~min}$ (see Figure 2). Then for changes in both parameters it can be noted that the estimate of the concentration remains correct $(t=45 \min y \mathrm{t}=100 \mathrm{~min})$, which shows that the scheme of Figure 1 is robust with the parametric changes. That is, for parametric changes the observer responds correctly, estimating the variable of interest without steady-state error. Likewise, Figures 3 and 4 show the correct estimation of the parameters for changes in the initial condition and changes in the process. 


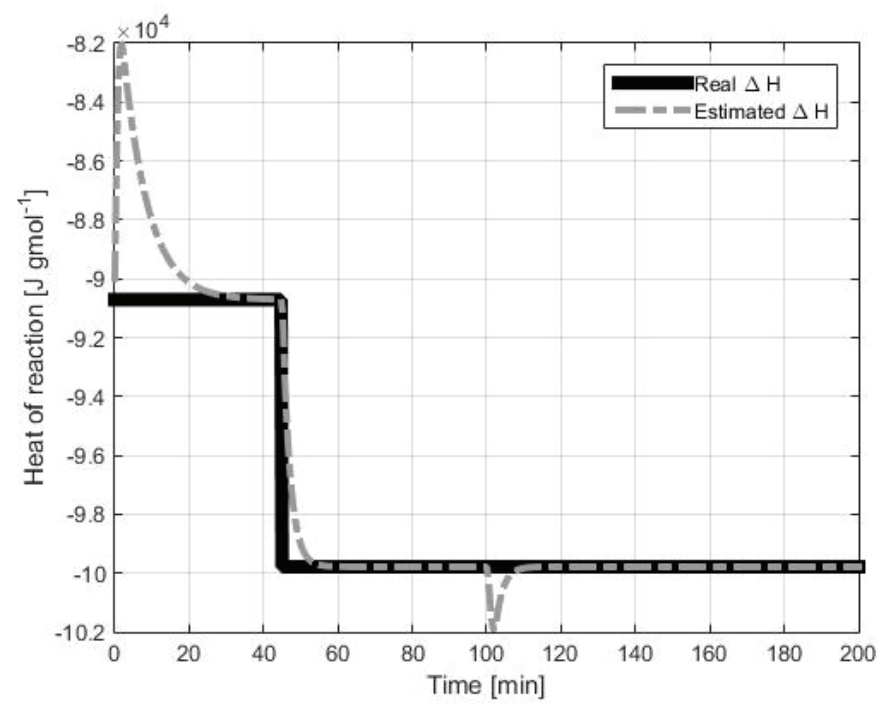

Figure 3. Heat of reaction $\Delta H$ (real and estimated).

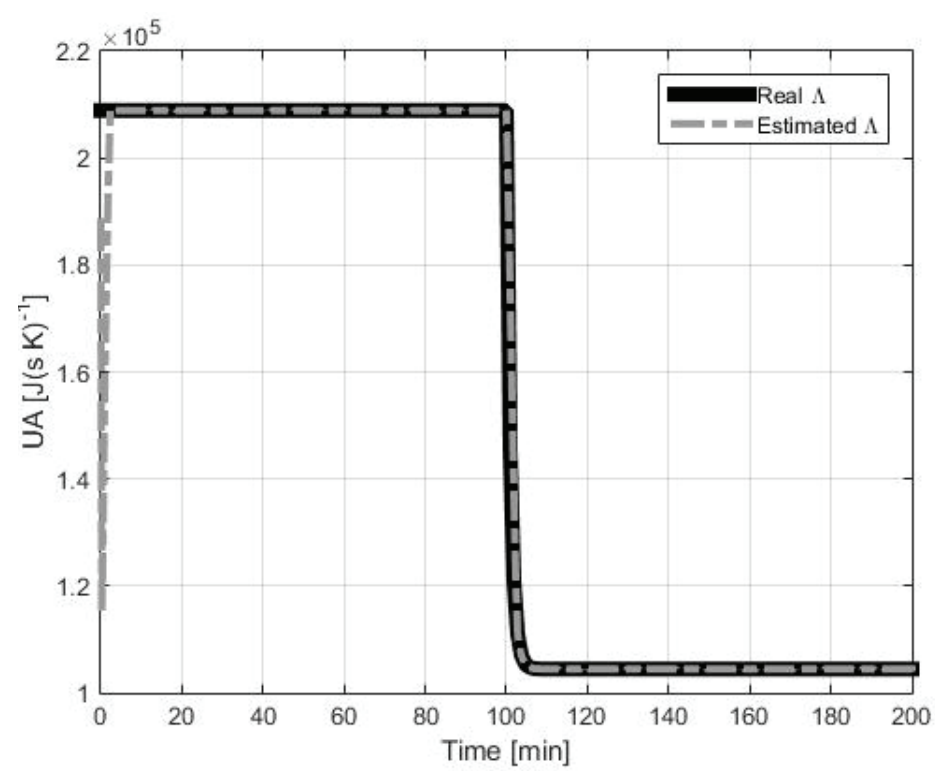

Figure 4. Global co efficient of heat transfer $\Lambda$ (real and estimated).

\section{Noisy measurements}

In this subsection, there is assumed that the temperature measurements were corrupted by a normally distributed random signal with zero mean and 0.1111 variance; this assumed variance responds to the fact that many temperature sensors report an accuracy of $\pm 1[K]$.

Figures 5 to 8 show the temperature inside the jacket $T_{j}$ the concentration of reactive inside the reactor $C_{A}$, the heat of reaction $\Delta H$ and the global coefficient of heat transfer $\Lambda$, respectively, for noisy measurements.

Based on the presented figures, a good performance of the proposed scheme is observed, also under noisy measurement conditions.

The measurement noise is filtered by the estimation algorithms (Figure 5), this way the estimated concentration convergence is similar to the noiseless convergence.

Also the fast and accurate convergence of the estimated parameters can be highlighted, although a little deviation is noted in the estimated heat of the reaction due to the high gain of the observer for this case. The HOSMO presents a correct estimation due to its capacity to calculate the parameters (Figures 7 and 8). 
In addition, the simultaneous estimation of $\Delta H$ and $\Lambda$ using the OBE makes the proposed system robust against this parameter variations under noise conditions, the estimated temperature inside the jacket is much closer to its real value than its measurement (Figure 5) and the estimated concentration remains correct, without steady-state error. Similarly to the noiseless measurements case the scheme is robust with the parametric changes.

Besides, it can be noted that the HOSMO presents reduced chattering due to the use of the second order differentiator; with this proposal, all discontinuities that produce chattering come up at the second time derivative, not at the first which is used in the estimation.

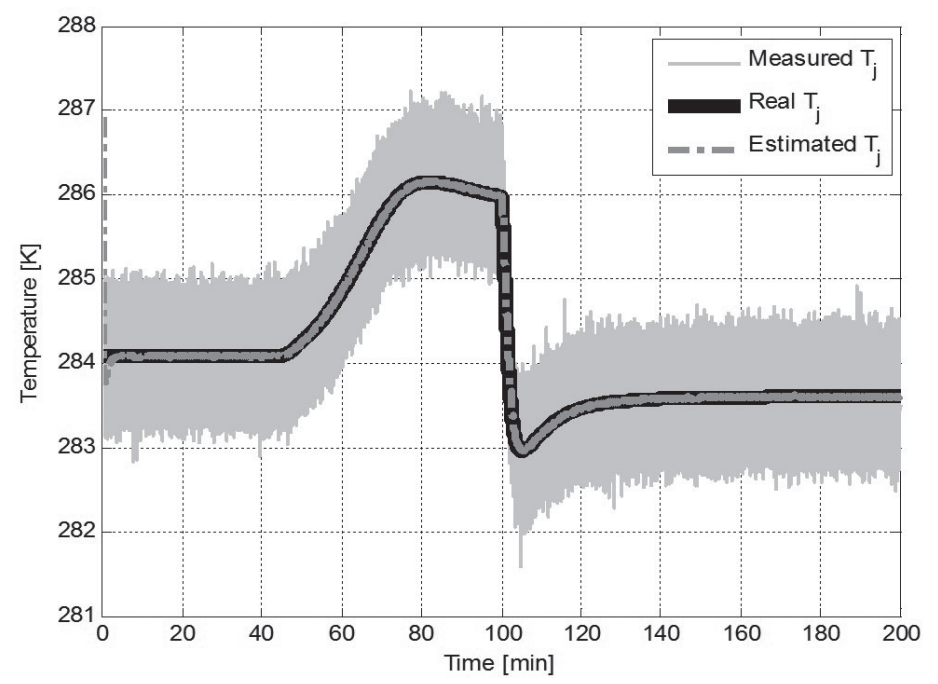

Figure 5. Temperature inside the jacket $T_{j}$ (real, estimated and measured).

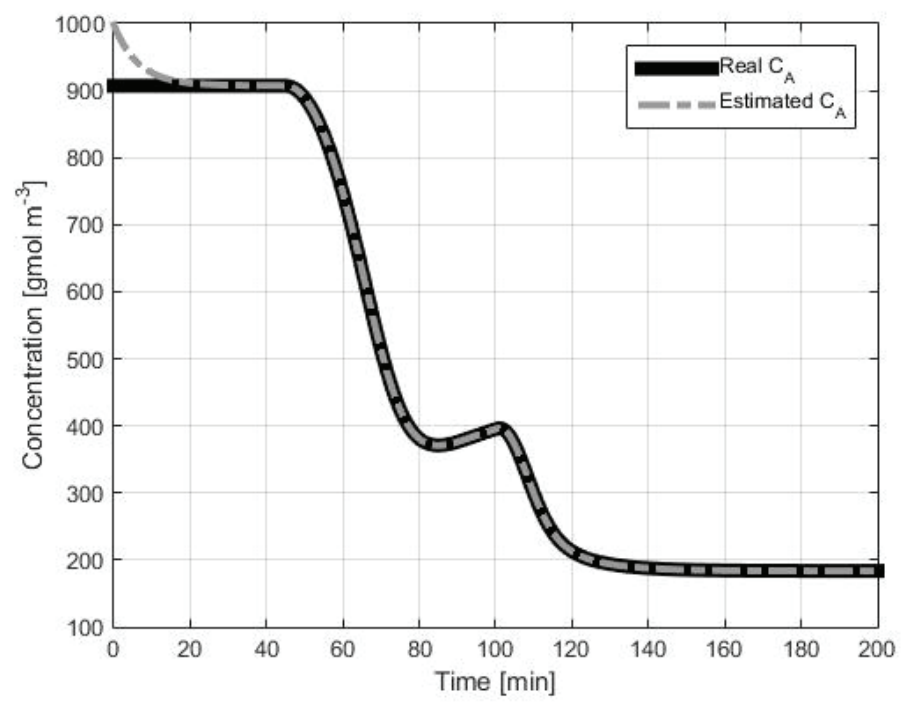

Figure 6. Concentration of the reactive inside the reactor $\mathrm{CA}$ (real and estimated). 


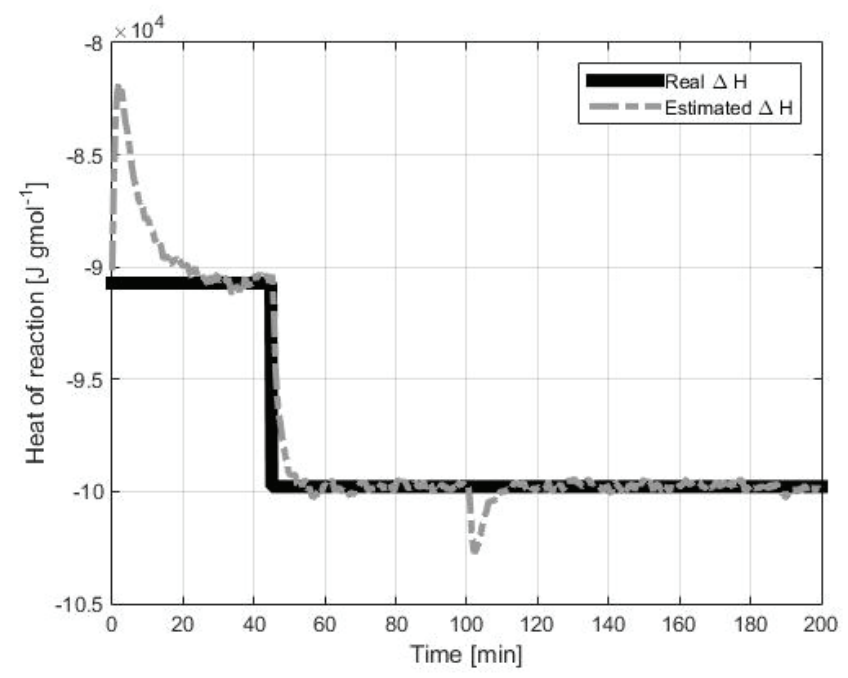

Figure 7. Heat of reaction $\Delta \mathrm{H}$ (real and estimated).

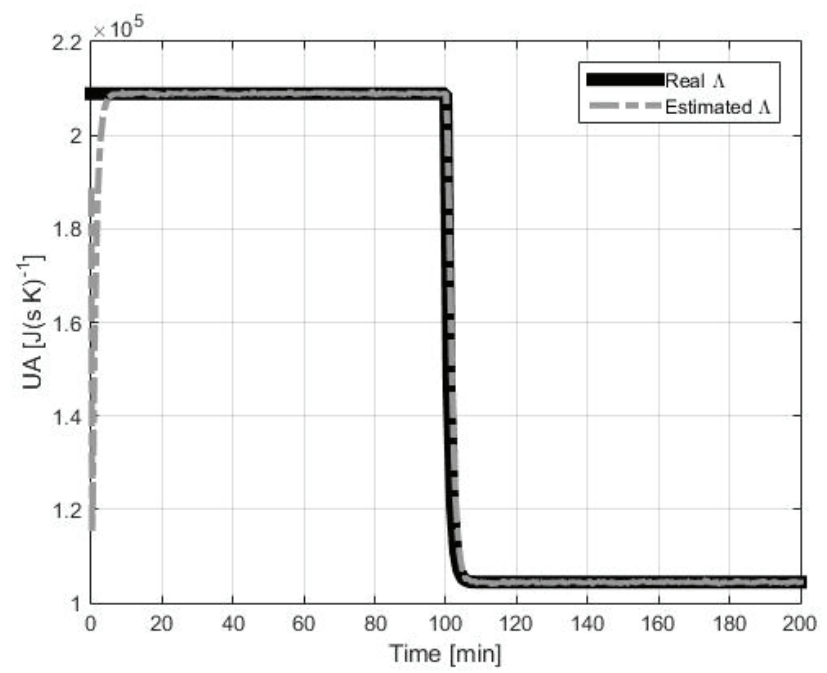

Figure 8. Global coefficient of heat transfer $\Lambda$ (real and estimated).

\section{Conclusions}

An estimation structure for a CSTR based on a second order sliding mode extension of an OBE coupled to a HOSMO was proposed. This scheme, apart from allowing state estimation, allows estimating two parameters of the process, which are well known as very difficult to measure, especially for real-time applications. One of these parameters was considered as an unknown parameter in the HOSMO, and the second one is estimated by a second order sliding mode OBE. Hence, this configuration ensures a state estimation that is robust against variations of the mentioned parameters. With a suitable selection of the observer parameters, the structure presents a fast convergence with high accuracy.

Numerical simulations show a good performance of the proposed approach, exposing some features as the accurate estimation of both parameter and state, robustness against these parameter variations, and a short-time convergence of the whole system, also under noisy-measurement conditions. Furthermore, the proposed estimation scheme presents reduced chattering presence due to the use of a second order differentiator instead of a first order one. The proposed approach can be extended to more complex processes with similar structures. For these cases, the computational burden can increase. 


\section{Acknowledgements}

Juan Diego Sánchez acknowledges to CONACyT, México for the PhD scholarship number 240280 and the support of Proyecto de Movilidad Internacional de la Diáspora Científica de Alto Reconocimiento, año 2012 Colciencias - Banco Mundial to his internship in Colombia.

\section{References}

[1] Walcott BL, Corless MJ, Zak SH. Comparative study of nonlinear state observation techniques. Int J Control. 1987;45:2109-32.

[2] Utkin VI. Sliding Modes in Control and Optimization. SciencesNew York. 1992. 286 p.

[3] Drakunov SV. Sliding-mode observers based on equivalent control method. [1992] Proc 31st IEEE Conf Decis Control. 1992;

[4] Spurgeon SK. Sliding mode observers: a survey. Int J Syst Sci. 2008;39:751-64.

[5] Drakunov SV, Utkin VI. Sliding mode control in dynamic systems. International Journal of Control. 1992. p. 1029-37.

[6] Drakunov S, Utkin V. Sliding mode observers. Tutorial. Proc 1995 34th IEEE Conf Decis Control. 1995;4.

[7] Cruz-Zavala E, Moreno JA, Fridman L. Uniform Second-Order Sliding Mode Observer for mechanical systems. Proceedings of the 2010 11th International Workshop on Variable Structure Systems, VSS 2010. 2010. p. 14-9.

[8] Polyakov A. Fixed-time stabilization of linear systems via sliding mode control. 2012 12th Int Work Var Struct Syst. 2012;1-6.

[9] Boukhobza T, Barbot J-P. High order sliding modes observer. Decision and Control, 1998. Proceedings of the 37th IEEE Conference on. 1998. p. 1912-7 vol.2.

[10] Angulo MT, Moreno JA, Fridman L. Some remarks about the tradeoffs between exactness and robustness in control. Proceedings of IEEE International Workshop on Variable Structure Systems. 2012. p. 82-7.

[11] Barbot J, Djemai M, Boukhobza TT. Sliding Mode Control In Engineering. Marcel Dekker. 2002.

[12] Utkin VI, Guldner J, Shi J. Sliding Mode Control in Electro-Mechanical Systems. Second Edi. (Automation and Control Engineering), editor. 2009.

[13] Levant A. Sliding order and sliding accuracy in sliding mode control. Int $\mathrm{J}$ Control.
1993;58(6):1247-63.

[14] Slotine J-JESJ-JE, Hedrick JKHJK, Misawa EAMEA. Nonlinear state estimation using sliding observers. 1986 25th IEEE Conf Decis Control. 1986;25.

[15] Drakunov SV. An adaptive quasioptimal filter with discontinuous parameter. Autom Remote Control. 1983;44:1167-75.

[16] Wang GB, Peng SS, Huang HP. A sliding observer for nonlinear process control. Chem Eng Sci. 1997;52(5):787-805.

[17] Drakunov SV, Law VJ. Parameter Estimation Using Sliding Mode Observers: Application to the Monod Kinetic Model. Chem Prod Process Model. 2007;2(3).

[18] Martínez-Guerra R, Aguilar R, Poznyak A. A new robust sliding-mode observer design for monitoring in chemical reactors. J Dyn Syst Meas Control. 2004;126:473-8.

19] Sbarciog M, Moreno JA, Vande Wouwer A. Application of super-twisting observers to the estimation of state and unknown inputs in an anaerobic digestion system. Water Sci Technol. 2014;69:414-21.

[20] Botero H, Álvarez H. Non Linear State and Parameters Estimation in Chemical Processes: Analysis and Improvement of Three Estimation Structures Applied to a CSTR. International Journal of Chemical Reactor Engineering. 2011.

[21] Osorio BG, Castro HB, Torres JDS. State and unknown input estimation in a CSTR using higher-order sliding mode observer. 2011 IEEE 9th Latin American Robotics Symposium and IEEE Colombian Conference on Automatic Control, LARC 2011 - Conference Proceedings. 2011.

[22] Fridman L, Shtessel Y, Edwards C, Yan XG. Higher-order sliding-mode observer for state estimation and input reconstruction in nonlinear systems. Int J Robust Nonlinear Control. 2008;18:399-412.

[23] Levant A. Robust exact differentiation via sliding mode technique. Automatica. 1998. p. 379-84.

[24] Bequette BW. Behavior of a CSTR with a recirculating jacket heat transfer system. Proc 2002 Am Control Conf (IEEE Cat NoCH37301). 2002;4.

[25] Poling B, Prausnitz J, O'Connell J. The Properties of Gases and Liquids. McGrawHill; 2001.

[26] Oliveira R, Ferreira EC, Feyo de Azevedo S. Stability, dynamics of convergence and tuning of observer-based kinetics estimators. J Process Control. 2002;12(2):311-23. 